\title{
Plasma Concentrations of Fibroblast Growth Factors 21 and 19 in Patients with Cushing's Syndrome
}

\author{
V. D̆UROVCOVÁ ${ }^{1}$, J. MAREK $^{1}$, V. HÁNA ${ }^{1}$, M. MATOULEK ${ }^{1}$, V. ZIKÁN ${ }^{1}$, \\ D. HALUZÍKOVÁ ${ }^{1,2}$, P. KAVÁLKOVÁ ${ }^{1}$, Z. LACINOVÁ ${ }^{1}$, M. KRŠEK ${ }^{1}$, M. HALUZÍK ${ }^{1}$ \\ ${ }^{1}$ Third Department of Medicine, ${ }^{2}$ Department of Sports Medicine, First Faculty of Medicine, \\ Charles University and General University Hospital, Prague, Czech Republic
}

Received April 6, 2009

Accepted June 26, 2009

On-line August 12, 2009

\section{Summary}

The objective of this study was to measure plasma fibroblast growth factor 21 and 19 (FGF21 and FGF19) levels in patients with Cushing's syndrome (CS) and to compare it with those of lean control subjects (C) and patients with obesity (OB). Fourteen untreated patients with CS, 19 patients with $O B$ and 36 controls were included in the study. Plasma FGF21 and FGF19 levels were measured by ELISA kits, other hormonal and biochemical parameters were measured by standard laboratory methods. Plasma FGF19 did not significantly differ among the studied groups. Plasma FGF21 levels were significantly higher in both $\mathrm{CS}$ and $\mathrm{OB}$ groups relative to $\mathrm{C}$ group but they did not differ between $\mathrm{CS}$ and $\mathrm{OB}$ groups. In a combined population of all three groups FGF21 levels positively correlated with BMI, waist circumference and percentage of total and truncal fat mass. Less prominent inverse relationship with these parameters was found for FGF19. Neither FGF21 nor FGF19 were significantly related to cortisol concentrations. Increased FGF21 concentrations in both patients with $\mathrm{CS}$ and $\mathrm{OB}$ relative to lean subjects suggest that excessive body fat and/or related metabolic abnormalities rather than direct effects of cortisol are responsible. In contrast neither obesity nor hypercortisolism significantly affected FGF19 concentrations.

\section{Key words}

Fibroblast growth factor 21 - Fibroblast growth factor 19 • Hypercortisolism • Obesity

\section{Corresponding author}

Martin Haluzik, $3^{\text {rd }}$ Department of Medicine, $1^{\text {st }}$ Faculty of Medicine, Charles University, General University Hospital, U Nemocnice 1, 12800 Prague 2, Czech Republic. Fax: +420 224919 780. E-mail: mhalu@lf1.cuni.cz

\section{Introduction}

Members of the fibroblast growth factor (FGF) family are involved in numerous cellular processes including growth, angiogenesis, and development (Böttcher and Niehrs 2005, Grose and Dickson 2005, Presta et al. 2005). Recent findings indicate that FGF21 and FGF19 may regulate metabolic homeostasis in paracrine and/or endocrine manner (Tomlinson et al. 2002, Fu et al. 2004, Kharitonenkov et al. 2005, Wente et al. 2006).

FGF21 is expressed primarily in liver (Nishimura et al. 2000). Recent studies have demonstrated that FGF21 is powerful stimulator of glucose uptake and lipolysis in adipose tissue (Kharitonenkov et al. 2005). Experimental studies have shown strong antiinflammatory, antidiabetic and hypolipidemic effects of FGF21 administration in both rodents and primates (Kharitonenkov et al. 2005, Wente et al. 2006, Kharitonenkov et al. 2007). In mice, the expression of FGF21 in liver is tightly nutritionally regulated. It is increased by starvation and ketogenic state (Inagaki et al. 2007, Badman et al. 2007, Lundåsen et al. 2007) and decreased by feeding (Badman et al. 2007). FGF21 levels are also regulated by nutritional state in humans. They are increased in patients with obesity and/or type 2 diabetes mellitus and decreased in malnourished patients with anorexia nervosa (Dostálová et al. 2008, Dostálová et al. 2009).

FGF19 is another recently characterized member of FGF family (Nishimura et al. 1999, Xie et al. 1999). Transgenic mice overexpressing human FGF19 have 
increased metabolic rate and decreased adiposity (Tomlinson et al. 2002, Fu et al. 2004). Circulating FGF19 exhibits a diurnal rhythm controlled by transintestinal bile acid flux. This diurnal rhythm of FGF19 is abolished by fasting (Lundåsen et al. 2006). In humans, FGF19 originates from intestine and modulates hepatic bile acids synthesis (Jones 2008). To our knowledge the only information concerning changes of FGF19 in humans is available in our recently published paper showing that severe malnutrition in patients with anorexia nervosa does not affect circulating levels of FGF19 (Dostálová et al. 2008).

To our best knowledge neither FGF21 nor FGF19 have been studied in patients with Cushing's syndrome. Here we tested the hypothesis that chronically increased cortisol levels in patients with Cushing's syndrome may alter circulating levels of FGF21 and FGF19. Such alterations could in turn contribute to some metabolic disturbances seen in these patients. Since patients with Cushing's syndrome frequently suffer from visceral obesity, insulin resistance/diabetes, arterial hypertension and other abnormalities similarly as patients with metabolic syndrome, we compared their FGF21 and FGF19 concentrations with both lean healthy control subjects and patients with obesity and type 2 diabetes mellitus.

\section{Methods}

\section{Study subjects}

Fourteen patients with active Cushing's syndrome (12 women, 2 men, age: $45.8 \pm 3.39$ years, body mass index (BMI): $33.7 \pm 1.42 \mathrm{~kg} / \mathrm{m}^{2}$ ), nineteen obese patients (17 women, 2 men, age: $54.6 \pm 3.3$ years, BMI: $45.8 \pm 2.42 \mathrm{~kg} / \mathrm{m}^{2}$ ) and thirty six healthy controls (28 women, 8 men, age: $43 \pm 2.07$ years, BMI: $22.7 \pm 0.26$ $\mathrm{kg} / \mathrm{m}^{2}$ ) were included in the study.

The diagnosis of Cushing's syndrome (CS) was based on clinical status, diminished circadian rhythm of cortisolemia (nocturnal cortisol over $150 \mathrm{nmol} / \mathrm{l}$ ), unsuppressed cortisolemia in $1 \mathrm{mg}$ Dexamethasone test (cortisol over $86 \mathrm{nmol} / \mathrm{l}$ ) and increased free urinary cortisol excretion (urinary free cortisol over 500 nmol/day). All 14 patients with CS had arterial hypertension, 12 of them already had been treated pharmacologically, 11 of them with a combination of antihypertensive drugs (with ACE inhibitors or sartans in 10 cases, calcium channel blockers in 6 cases, betablockers in 8 cases, diuretics in 7 cases, imidazoline receptor antagonist in one case and an alpha-blocker in one case). All patients had clinical signs of abdominal fat accumulation as measured by increased waist circumference. Twelve patients had disturbances in serum lipid spectrum (10 patients had elevated total and LDL (low density lipoprotein) cholesterol levels, in 7 cases together with elevated triglycerides, in 3 patients also with decreased HDL (high density lipoprotein) cholesterol levels; 2 patients had only elevated triglycerides and decreased HDL cholesterol serum concentrations). One patient had been already treated with a combination of statin and fibrate. One patient was diagnosed with impaired glucose tolerance (IGT), nine patients with type 2 diabetes mellitus (DM) - four of them had been treated, three with antidiabetic drugs (PAD), one with a combination of PAD and insulin.

The group of patients with obesity (OB) was characterized by BMI over $30 \mathrm{~kg} / \mathrm{m}^{2}$. Sixteen out of nineteen patients in this group had arterial hypertension, all had already been on antihypertensive treatment, thirteen of them on a combination of antihypertensive drugs (with ACE inhibitors or sartans in 14 cases, calcium channel blockers in 4 cases, beta-blockers in 10 cases, diuretics in 11 cases and imidazoline receptor antagonist in 3 cases). Fifteen patients had pathological serum lipid spectrum (10 patients had elevated total and LDL cholesterol levels, in 2 cases together with elevated triglycerides and decreased HDL cholesterol, in 5 cases only with HDL cholesterol decrease; 2 patients had elevated triglycerides in combination with decreased HDL cholesterol and 3 patients had isolated HDL cholesterol decrease). Eight patients had already been treated, either with fibrate or statin, one patient with a combination of both. Two patients had impaired fasting glucose (IFG) levels, four patients were diagnosed with IGT and nine patients had type $2 \mathrm{DM}$, all treated either with PAD, insulin or its combination.

The healthy controls (C) had no history of obesity or malnutrition, arterial hypertension, glucose or lipid metabolism disturbances, malignant tumors or other severe co-morbidities. They had no regular medication (except for hormonal contraceptives in five women). Blood tests confirmed normal blood count, biochemical and hormonal parameters.

All subjects were asked to fast and drink only water a night long prior to the study. Written informed consent was signed by all participants before being enrolled in the study. The study was approved by the Ethical Committee, First Faculty of Medicine, Charles 
University and General Teaching Hospital, Prague, Czech Republic, and was performed in accordance with the guidelines proposed in the Declaration of Helsinki.

\section{Anthropometric examination and blood sampling}

All patients were examined in the morning at a basal state. All subjects were weighted and measured. A percentage of truncal body fat was assessed by body composition measurement using Dual-Energy X-Ray Absorptiometry (DEXA, Hologic Discovery, USA). Percentage of total body fat was examined by bioimpedance (Multi-frequency Bodystat QuadScan 4000, Douglas, British Isles) at body current flow of 5, 50, 100 and $200 \mathrm{kHz}$, respectively. Resting energy expenditure (REE) and respiratory quotient (RQ) were measured by indirect calorimetry (V Max Encore 29N, Viasys, Pennsylvania, USA) performed with a ventilated hood system. Oxygen consumption and carbon dioxide production were measured, and energy expenditure was calculated by using the formula of Weir (1949). Blood samples for measurement of FGF21, FGF19, resistin, adiponectin, leptin, insulin and biochemical parameters were withdrawn between 7 and 8 a.m. after 12 hours of overnight fasting. Plasma samples for FGF21 and FGF19 analysis were collected into polypropylene tubes containing $\mathrm{Na}_{2}$ EDTA. Plasma was separated by centrifugation at room temperature and stored at $-80{ }^{\circ} \mathrm{C}$ until being assayed.

\section{Hormonal and biochemical assays}

Plasma FGF21 concentrations were measured by a commercial ELISA kit (BioVendor, Brno, Czech Republic). The samples were diluted with Dilution Buffer $1: 1$ or $2: 1$, respectively. The sensitivity was $5.0 \mathrm{pg} / \mathrm{ml}$, and the intra- and interassay variability was 5.0 and $9.0 \%$, respectively. Plasma FGF19 concentrations were measured by a commercial ELISA kit (BioVendor, Brno, Czech Republic). The samples were diluted with Dilution Buffer $1: 1$. The sensitivity was $4.8 \mathrm{pg} / \mathrm{ml}$, and the intraand interassay variability was 7.0 and $8.5 \%$, respectively.

Serum insulin concentrations were measured by a commercial RIA kit (Cis Bio International, Gif-surYvette, France). Sensitivity was $2.0 \mu \mathrm{IU} / \mathrm{ml}$, and the intra- and interassay variability was 4.2 and $8.8 \%$, respectively. Serum leptin concentrations were measured by a commercial ELISA kit (BioVendor, Brno, Czech Republic). Sensitivity was $0.12 \mathrm{ng} / \mathrm{ml}$, and the intra- and interassay variability was 1.7 and $8.0 \%$, respectively. Serum adiponectin concentrations were measured by a commercial ELISA kit (Linco Research, St. Charles, Missouri, USA). Sensitivity was $0.78 \mathrm{ng} / \mathrm{ml}$, and the intra- and interassay variability was 3.4 and $5.7 \%$, respectively. Serum resistin concentrations were measured by a commercial ELISA kit (BioVendor, Brno, Czech Republic). Sensitivity was $0.2 \mathrm{ng} / \mathrm{ml}$, and the intraand interassay variability was 3.1 and $6.5 \%$, respectively.

Serum levels of insulin-like growth factor-1 (IGF-1) were measured by a commercial IRMA kit (Immunotech, Prague, Czech Republic). Sensitivity was $2 \mathrm{ng} / \mathrm{ml}$, and the intra- and interassay variability was 6.3 and $6.8 \%$, respectively. Plasma levels of cortisol were measured by a commercial RIA kit (Immunotech, Prague, Czech Republic). Sensitivity was $10 \mathrm{nmol} / \mathrm{l}$, and the intra- and interassay variability was 5.8 and $9.2 \%$, respectively. Serum biochemical parameters (glucose, total and HDL-cholesterol and triglycerides) were measured by standard laboratory methods on Hitachi analyzer, the value of LDL-cholesterol was calculated. Glycated hemoglobin was analyzed by high performance liquid chromato-graphy (HPLC) on Variant II BioRad analyzer. TSH, fT4 and fT3 were measured using chemiluminiscence imunoassay (CLIA) on ADVIA: Centaur analyzer.

\section{Statistical analysis}

The statistical analysis was performed using SigmaStat software (Jandel Scientific, San Rafael, CA). Results are expressed as means \pm SEM or median, upper and lower quartiles, minimum and maximum values. ANOVA test, followed by Dunn's test was used for groups' comparison. The correlations between the values were estimated by Spearman correlation test. A p value $<0.05$ denoted statistical significance.

\section{Results}

Anthropometric and metabolic characteristics of study subjects

Ten out of 14 patients with CS had BMI in the range of obesity, and all had signs of abdominal fat accumulation with waist circumference increased over normal values ( $>80 \mathrm{~cm}$ in women, $>94 \mathrm{~cm}$ in men). The waist circumference of $\mathrm{OB}$ patients was significantly higher in comparison with CS group (Table 1). The systolic and diastolic blood pressure was significantly higher in both $\mathrm{CS}$ and $\mathrm{OB}$ groups relative to $\mathrm{C}$, but it was also significantly higher in patients with $\mathrm{CS}$ as compared to OB group (Table 1). 
Table 1. Anthropometric, biochemical and hormonal characteristics of patients with Cushing's syndrome (CS), obesity (OB) and control subjects (C).

\begin{tabular}{|c|c|c|c|}
\hline & $\operatorname{CS}(n=14)$ & OB $(n=19)$ & $C(n=36)$ \\
\hline Age (years) & $45.8 \pm 3.39$ & $54.6 \pm 3.3$ & $43.0 \pm 2.07$ \\
\hline Body mass index $\left(\mathrm{kg} / \mathrm{m}^{2}\right)$ & $33.7 \pm 1.42 *$ & $45.8 \pm 2.42 *$ & $22.7 \pm 0.26$ \\
\hline Waist circumference $(\mathrm{cm})$ & $110.6 \pm 3.38 *, \square$ & $127.2 \pm 4.26 *$ & $77.5 \pm 1.72$ \\
\hline Systolic blood pressure (mm Hg) & $153.6 \pm 5.2^{*, \square}$ & $134.5 \pm 3.96 *$ & $111.0 \pm 2.92$ \\
\hline Diastolic blood pressure ( $\mathrm{mm} \mathrm{Hg}$ ) & $91.4 \pm 3.41 *, \square$ & $77.5 \pm 1.94 *$ & $70.0 \pm 1.83$ \\
\hline$\%$ of total body fat (bioimpedance) & $40.0 \pm 2.37^{*, \square}$ & $51.1 \pm 2.44 *$ & $18.8 \pm 2.01$ \\
\hline$\%$ of truncal body fat (DEXA) & $44.0 \pm 1.33 *$ & $41.2 \pm 2.8 *$ & $20.7 \pm 1.19$ \\
\hline$R E E / k g(k c a l / d a y / k g)$ & $17.9 \pm 0.42 *$ & $16.0 \pm 0.75 *$ & $22.5 \pm 0.47$ \\
\hline Respiratory quotient & $0.79 \pm 0.02 \square$ & $0.71 \pm 0.01 *$ & $0.79 \pm 0.01$ \\
\hline Glucose (mmol/l) & $6.4 \pm 1.03 *$ & $7.8 \pm 0.85 *$ & $4.5 \pm 0.12$ \\
\hline Insulin $(\mu U I / m l)$ & $85.1 \pm 38.66 *$ & $44.4 \pm 10.57 *$ & $15.3 \pm 1.4$ \\
\hline HOMA index & $20.7 \pm 8.01 *$ & $15.3 \pm 3.69 *$ & $3.2 \pm 0.35$ \\
\hline Glycated hemoglobin Alc (\%) & $5.6 \pm 0.6^{*}$ & $5.7 \pm 0.48 *$ & $3.7 \pm 0.07$ \\
\hline Total cholesterol (mmol/l) & $5.7 \pm 0.38$ & $4.9 \pm 0.21$ & $5.1 \pm 0.14$ \\
\hline LDL-cholesterol (mmol/l) & $3.6 \pm 0.32$ & $2.9 \pm 0.22$ & $3.1 \pm 0.12$ \\
\hline HDL-cholesterol (mmol/l) & $1.2 \pm 0.06 *$ & $1.1 \pm 0.07 *$ & $1.5 \pm 0.08$ \\
\hline Triglycerides (mmol/l) & $2.1 \pm 0.27 *$ & $2.7 \pm 0.89 *$ & $1.0 \pm 0.07$ \\
\hline Leptin $(n g / m l)$ & $60.2 \pm 5.36 *$ & $55.7 \pm 4.49 *$ & $9.3 \pm 1.38$ \\
\hline Resistin $(n g / m l)$ & $7.5 \pm 0.65 *$ & $7.9 \pm 1.38$ & $5.4 \pm 0.34$ \\
\hline Adiponectin (ng/ml) & $17.0 \pm 1.84$ & $17.8 \pm 1.83$ & $22.4 \pm 1.75$ \\
\hline fT3 (pmol/l) & $4.1 \pm 0.17^{*, \square}$ & $5.1 \pm 0.47$ & $5.1 \pm 0.16$ \\
\hline fT4 (pmol/l) & $13.7 \pm 0.67^{*, \square}$ & $16.2 \pm 0.51$ & $15.8 \pm 0.46$ \\
\hline TSH (mIU/l) & $0.9 \pm 0.19^{*, \square}$ & $2.2 \pm 0.33$ & $2.3 \pm 0.59$ \\
\hline$I G F-1(u g / l)$ & $282.5 \pm 33.89$ & $199.1 \pm 20.10$ & $223.0 \pm 22.12$ \\
\hline Basal plasma cortisol (nmol/l) & $946.3 \pm 8.2^{*, \square}$ & $515.3 \pm 38.4$ & $611.4 \pm 33.75$ \\
\hline$F G F 19(\mathrm{pg} / \mathrm{ml})$ & $149.8 \pm 22.54$ & $172.0 \pm 26.96$ & $234.8 \pm 26.6$ \\
\hline
\end{tabular}

$* p<0.05$ vs. C group, ${ }^{\square} p<0.05$ for CS vs. OB group. Values are means \pm SEM. Statistical significance is from one-way ANOVA. DEXA Dual-Energy X-Ray Absorptiometry; REE - resting energy expenditure; HOMA - homeostatic model assessment of insulin resistance; LDL - low density lipoprotein; HDL - high density lipoprotein; fT3 - free triiodothyronine; fT4 - free thyroxine; TSH - thyroid stimulating hormone; IGF-1 - insulin-like growth factor-1; FGF19 - fibroblast growth factor 19

The percentage of total and truncal body fat was significantly higher in CS and OB subjects relative to C. Percentage of total body fat was significantly higher in OB relative to CS group. REE per $\mathrm{kg}$ was significantly higher in $\mathrm{C}$ compared to $\mathrm{CS}$ and $\mathrm{OB}$ with no difference between $\mathrm{CS}$ and $\mathrm{OB}$, whereas RQ was significantly lower in $\mathrm{OB}$ patients relative to $\mathrm{CS}$ and $\mathrm{C}$, with no difference between CS and C subjects (Table 1).

Serum levels of hormonal and biochemical parameters: comparison of $C S, O B$ and $C$ subjects

Fasting serum glucose, insulin, HOMA index (homeostatic model assessment of insulin resistance) and glycated hemoglobin were significantly higher in both CS and $\mathrm{OB}$ patients relative to $\mathrm{C}$, but with no significant difference between CS and OB group (Table 1). HDL cholesterol was significantly reduced in $\mathrm{CS}$ and $\mathrm{OB}$ relative to $\mathrm{C}$, but did not differ between $\mathrm{CS}$ and $\mathrm{OB}$ subjects. Triglycerides were significantly increased in CS and $\mathrm{OB}$ group in comparison with $\mathrm{C}$. There were no significant differences in total and LDL cholesterol levels between the studied groups (Table 1).

Both fasting serum leptin and resistin were significantly higher in CS as compared to C. Leptin levels were significantly higher in $\mathrm{OB}$ relative to $\mathrm{C}$ subjects. No significant differences were found in adiponectin levels between the examined groups (Table 1).

$\mathrm{TSH}$, free $\mathrm{T} 3$ and free $\mathrm{T} 4$ were significantly 
lower in CS as compared to OB and C. Basal plasma cortisol was significantly higher in $\mathrm{CS}$ relative to $\mathrm{OB}$ and $\mathrm{C}$ patients. There were no significant differences in serum IGF-1 concentrations between the studied groups (Table 1).

Plasma levels of FGF21 and FGF19: comparison of CS, $O B$ and $C$ subjects

Fasting plasma FGF21 levels were significantly higher in $\mathrm{CS}$ and $\mathrm{OB}$ subjects relative to $\mathrm{C}$. There was no significant difference in FGF21 levels between CS and OB patients (Figure 1).

Plasma FGF19 levels did not significantly differ between the groups studied (Table 1). No statistically significant gender differences within the groups either in FGF21 or in FGF19 levels were found.

Relationship of FGF21 and FGF19 with other anthropometric, hormonal and biochemical parameters

The relationship of FGF21 and FGF19 with other studied parameters was calculated in the combined population of all three groups (Table 2).

Plasma FGF21 levels significantly positively correlated with BMI, waist circumference and percentage of total and truncal fat mass, systolic and diastolic blood pressure, triglyceride levels, HOMA index, insulin, glycated hemoglobin, leptin levels and were inversely related to HDL-cholesterol and adiponectin levels (Table 2).

Plasma FGF19 was significantly positively associated with HDL cholesterol levels and correlated inversely with BMI, waist circumference, percentage of total and truncal fat mass, systolic blood pressure, HOMA index, insulin, glycated hemoglobin and IGF-1 levels (Table 2).

We failed to find significant relationships between FGF21 and FGF19 and plasma cortisol, thyroid hormones, total and LDL cholesterol or resistin levels, respectively (Table 2).

\section{Discussion}

Numerous previous studies have shown that regulation of metabolic homeostasis is a very complex process involving not only traditional central and peripheral mechanisms but also novel factors produced by adipose tissue, liver and muscle (Anderlová et al. 2007, Haluzík et al. 2009, Havel 2002). FGF21 is an example of such factor being produced predominantly in

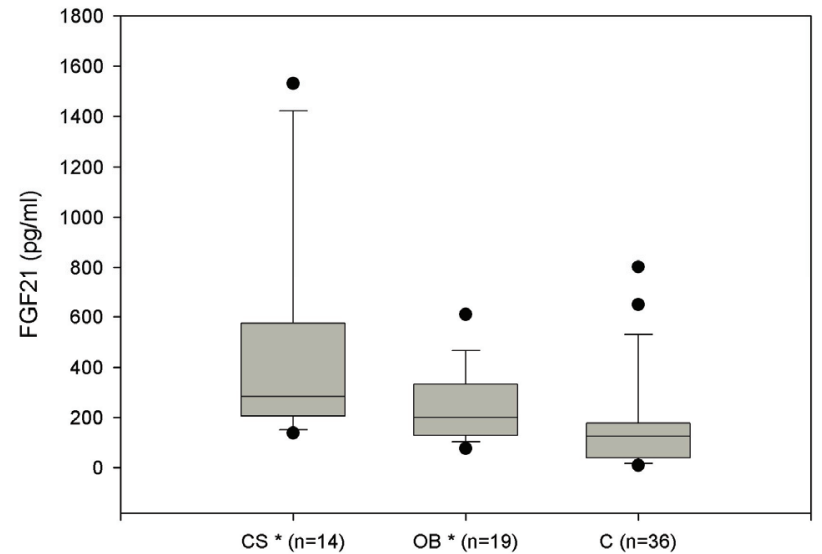

Fig. 1. Plasma fibroblast growth factor 21 (FGF21) concentrations in patients with Cushing's syndrome (CS), obesity (OB) and control subjects (C). Values are median, upper and lower quartiles, minimum and maximum data. Statistical significance is from one-way ANOVA and Dunn's test. * $p<0.05$ vs. $\mathrm{C}$ group

the liver and to lesser degree in the adipose tissue (Dostálová et al. 2009, Kharitonenkov and Shanafelt 2008). Here we show that plasma FGF21 levels are markedly increased in patients with Cushing's syndrome relative to healthy lean control subjects, but they do not significantly differ from those of patients with obesity and type 2 diabetes mellitus. This finding indicates that increased FGF21 concentrations in patients with Cushing's syndrome are very likely due to obesity and metabolic abnormalities induced by chronic hypercortisolism rather than due to direct effect of chronic hypercortisolemia on FGF21 production per se. Nevertheless, it should be noted that the cross-sectional design of our study does not allow us to unambiguously distinguish between the direct effects of cortisol and effects of obesity and related metabolic alterations, respectively. On the other hand, while FGF21 concentrations positively correlated with BMI, waist circumference and percentage of total and truncal fat mass, no such relationship was found between FGF21 and circulating cortisol levels arguing rather for an indirect mechanism.

Changes of FGF21 levels in patients with Cushing's syndrome are in agreement with previous findings that the presence of obesity and/or type 2 diabetes mellitus is accompanied by elevated FGF21 concentrations (Zhang et al. 2008, Mráz et al. 2009). We have recently shown that FGF21 mRNA expression is detectable not only in liver but also in both subcutaneous and visceral adipose tissue (Mráz et al. 2009). While no differences in FGF21 mRNA expression in subcutaneous fat were found 
Table 2. Relationships of fibroblast growth factor 21 and 19 (FGF21 and 19) with anthropometric, biochemical and hormonal parameters calculated in a combined population of patients with Cushing's syndrome, obesity and lean healthy controls $(n=69)$.

\begin{tabular}{lcccc}
\hline & \multicolumn{2}{c}{ FGF21 } & \multicolumn{2}{c}{ FGF19 } \\
\cline { 2 - 5 } & $\mathbf{R}$ & $\mathbf{p}$ & $\mathbf{r}$ & $\mathbf{p}$ \\
\hline Waist circumference & 0.413 & 0.003 & -0.324 & 0.02 \\
BMI & 0.344 & 0.006 & -0.279 & 0.017 \\
\% of total body fat & 0.393 & 0.016 & -0.283 & 0.044 \\
\% of truncal body fat & 0.428 & 0.009 & -0.334 & 0.043 \\
Systolic blood pressure & 0.367 & 0.007 & -0.271 & 0.048 \\
Diastolic blood pressure & 0.439 & $<0.001$ & $\mathrm{NS}$ & $\mathrm{NS}$ \\
HDL-cholesterol & -0.323 & 0.01 & 0.299 & 0.0143 \\
Triglycerides & 0.504 & $<0.001$ & $\mathrm{NS}$ & $\mathrm{NS}$ \\
Glucose & 0.421 & $<0.001$ & $\mathrm{NS}$ & $\mathrm{NS}$ \\
Insulin & 0.498 & $<0.001$ & -0.274 & 0.023 \\
HOMA index & 0.544 & $<0.001$ & -0.305 & 0.013 \\
HbA1c (\%) & 0.351 & 0.005 & -0.285 & 0.016 \\
Leptin & 0.438 & $<0.001$ & $\mathrm{NS}$ & $\mathrm{NS}$ \\
Adiponectin & -0.261 & 0.046 & $\mathrm{NS}$ & $\mathrm{NS}$ \\
IGF-1 & $\mathrm{NS}$ & $\mathrm{NS}$ & -0.325 & 0.022 \\
\hline
\end{tabular}

$\mathrm{r}$ - correlation coefficient; $\mathrm{p}$ - statistical significance; NS - non-significant. Results are from Spearman Correlation Test. BMI - body mass index; HDL - high density lipoprotein; HOMA - homeostatic model assessment of insulin resistance; HbA1c - glycated hemoglobin; IGF-1 - insulin-like growth factor-1

between the obese and the lean subjects, FGF21 mRNA expression in visceral fat increased significantly in the obese relative to the lean group. Nevertheless, adipose tissue mRNA expression was approximately 100-fold lower as compared to liver (Mráz et al. 2009).

FGF21 administration in both rodents and primates markedly improved numerous metabolic abnormalities including blood glucose, serum triglyceride and HDL levels (Kharitonenkov et al. 2005, Wente et al. 2006, Kharitonenkov et al. 2007). Furthermore, FGF21 treatment also decreased body weight in primates but not in mice (Kharitonenkov et al. 2005, Kharitonenkov et al. 2007). Increased FGF21 concentrations in patients with obesity and Cushing's syndrome thus might be somewhat paradoxical because these patients display insulin resistance, obesity and dyslipidemia. We suggest that increased FGF21 levels in these patients may represent a compensatory response to improve impaired insulin sensitivity and other unfavorable metabolic features.

In contrast to altered FGF21 concentrations we did not see any major differences in FGF19 levels either in patients with obesity or Cushing's syndrome relative to lean healthy individuals. Experimental studies in transgenic mice overexpressing FGF19 have shown numerous obvious metabolic changes including increased metabolic rate, decreased adiposity, increased food intake, decreased lipids and increased insulin sensitivity (Tomlinson et al. 2002, Fu et al. 2004). In contrast to FGF21 no data from primate studies concerning FGF19 administration are available suggesting the possibility of distinct functions of FGF19 in rodents and humans. Our results show that circulating FGF19 is not regulated either by nutritional status, the presence of insulin resistance/diabetes and/or chronically increased cortisol levels. We are aware that our results are based on a single measurement after overnight fasting and possible nutrition-related changes in the dynamic secretion pattern of FGF19 or its local alterations in the site of its production may not have been noticed here.

In conclusion, our study has shown that FGF21 levels are increased in both patients with simple obesity and obese patients with endogenous hypercortisolism, while no such alterations were found in FGF19 concentrations. We suggest that increased FGF21 concentrations in patients with Cushing's syndrome are rather due to their excessive fat accumulation and related metabolic abnormalities than due to a direct effect of cortisol on FGF21 production. 


\section{Conflict of Interest}

There is no conflict of interest.

\section{Acknowledgements}

Supported by grant of IGA MHCR No. NR/9438-3.

\section{References}

ANDERLOVÁ K, DOLEŽALOVÁ R, HOUSOVÁ J, BOŠANSKÁ L, HALUZÍKOVÁ D, KŘEMEN J, ŠKRHA J, HALUZÍK M: Influence of PPAR-alpha agonist fenofibrate on insulin sensitivity and selected adipose tissuederived hormones in obese women with type 2 diabetes. Physiol Res 56: 579-586, 2007.

BADMAN MK, PISSIOS P, KENNEDY AR, KOUKOS G, FLIER JS, MARATOS-FLIER E: Hepatic fibroblast growth factor 21 is regulated by PPARalpha and is a key mediator of hepatic lipid metabolism in ketotic states. Cell Metab 5: 426-437, 2007.

BÖTTCHER RT, NIEHRS C: Fibroblast growth factor signaling during early vertebrate development. Endocr Rev 26: 63-77, 2005.

DOSTÁLOVÁ I, HALUZÍKOVÁ D, HALUZÍK M: Fibroblast growth factor 21: a novel metabolic regulator with potential therapeutic properties in obesity/type 2 diabetes mellitus. Physiol Res 58: 1-7, 2009.

DOSTÁlOVÁ I, KAVÁLKOVÁ P, HALUZÍKOVÁ D, LACINOVÁ Z, MRÁZ M, PAPEŽOVÁ H, HALUZÍK M: Plasma concentrations of fibroblast growth factor 19 and 21 in patients with anorexia nervosa. $J$ Clin Endocrinol Metab 93: 3627-2632, 2008.

FU L, JOHN LM, ADAMS SH, YU XX, TOMLINSON E, RENZ M, WILLIAMS PM, SORIANO R, CORPUZ R, MOFFAT B, VANDLEN R, SIMMONS L, FOSTER J, STEPHAN JP, TSAI SP, STEWART TA: Fibroblast growth factor 19 increases metabolic rate and reverses dietary and leptin-deficient diabetes. Endocrinology 145: 2594-2603, 2004.

GROSE R, DICKSON C: Fibroblast growth factor signaling in tumorigenesis. Cytokine Growth Factor Rev 16: 179$186,2005$.

HALUZÍK MM, ANDERLOVÁ K, DOLEŽALOVÁ R, ADAMÍKOVÁ A, HALUZÍKOVÁ D, HOUSOVÁ J, SVAČINA S, HALUZÍK M: Serum adipocyte fatty acid binding protein levels in patients with type 2 diabetes mellitus and obesity: the influence of fenofibrate treatment. Physiol Res 58: 93-99, 2009.

HAVEL PJ: Control of energy homeostasis and insulin action by adipocyte hormones: leptin, acylation stimulating protein, and adiponectin. Curr Opin Lipidol 13: 51-59, 2002.

INAGAKI T, DUTCHAK P, ZHAO G, DING X, GAUTRON L, PARAMESWARA V, LI Y, GOETZ R, MOHAMMADI M, ESSER V, ELMQUIST JK, GERARD RD, BURGESS SC, HAMMER RE, MANGELSDORF DJ, KLIEWER SA: Endocrine regulation of the fasting response by PPAR $\alpha$-mediated induction of fibroblast growth factor 21. Cell Metab 5: 415-425, 2007.

JONES S: Mini-review: endocrine actions of fibroblast growth factor 19. Mol Pharm 5: 42-48, 2008.

KHARITONENKOV A, SHANAFELT AB: Fibroblast growth factor-21 as a therapeutic agent for metabolic diseases. BioDrugs 22: 37-44, 2008.

KHARITONENKOV A, SHIYANOVA TL, KOESTER A, FORD AM, MICANOVIC R, GALBREATH EJ, SANDUSKY GE, HAMMOND LJ, MOYERS JS, OWENS RA, GROMADA J, BROZINICK JT, HAWKINS ED, WROBLEWSKI VJ, LI DS, MEHRBOD F, JASKUNAS SR, SHANAFELT AB: FGF-21 as a novel metabolic regulator. $J$ Clin Invest 115: 1627-1635, 2005.

KHARITONENKOV A, WROBLEWSKI VJ, KOESTER A, CHEN YF, CLUTINGER CK, TIGNO XT, HANSEN BC, SHANAFELD AB, ETGEN GJ: The metabolic state of diabetic monkeys is regulated by fibroblast growth factor-21. Endocrinology 148: 774-781, 2007.

LUNDASEN T, GALMAN C, ANGELIN B, RUDLING M: Circulating intestinal fibroblast growth factor 19 has a pronounced diurnal variation and modulates hepatic bile acid synthesis in man. J Intern Med 260: 530-536, 2006.

LUNDASEN T, HUNT MC, NILSSON LM, SANYAL S, ANGELIN B, ALEXSON SE, RUDLING M: PPAR $\alpha$ is a key regulator of hepatic FGF21. Biochem Biophys Res Commun 360: 437-440, 2007. 
MRÁZ M, BARTLOVÁ M, LACINOVÁ Z, MICHALSKÝ D, KASALICKÝ M, HALUZÍKOVÁ D, MATOULEK M, DOSTÁLOVÁ I, HUMENANSKÁ V, HALUZÍK M: Serum concentrations and tissue expression of a novel endocrine regulator fibroblast growth factor-21 in patients with type 2 diabetes and obesity; Clin Endocrinol 71: 369-375, 2009.

NISHIMURA T, NAKATAKE Y, KONISHI M, ITOH N: Identification of a novel FGF, FGF-21, preferentially expressed in the liver. Biochim Biophys Acta 1492: 203-206, 2000.

NISHIMURA T, UTSUNOMIYA Y, HOSHIKAWA M, OHUCHI H, ITOH N: Structure and expression of a novel human FGF, FGF-19, expressed in the fetal brain. Biochim Biophys Acta 1444: 148-151, 1999.

PRESTA M, DELL'ERA P, MITOLA S, MORONI E, RONCA R, RUSNATI M: Fibroblast growth factor/fibroblast growth factor receptor system in angiogenesis. Cytokine Growth Factor Rev 16: 159-178, 2005.

TOMLINSON E, FU L, JOHN L, HULTGREN B, HUANG X, RENZ M, STEPHAN JP, TSAI SP, POWELLBRAXTON L, FRENCH D, STEWART TA: Transgenic mice expressing human fibroblast growth factor-19 display increased metabolic rate and decreased adiposity. Endocrinology 143: 1741-1747, 2002.

WEIR JB: New methods for calculating metabolic rate with special reference to protein metabolism. $J$ Physiol Lond 109: 1-9, 1949.

WENTE W, EFANOV AM, BRENNER M, KHARITONENKOV A, KOESTER A, SANDUSKY GE, SEWING S, TREINIES I, ZITZER H, GROMADA J: Fibroblast growth factor-21 improves pancreatic beta-cell function and survival by activation of extracellular signal-regulated kinase 1/2 and Akt signaling pathways. Diabetes 55: 2470-2478, 2006.

XIE MH, HOLCOMB I, DEUEL B, DOWD P, HUANG A, VAGTS A, FOSTER J, LIANG J, BRUSH J, GU Q, HILLAN K, DOGGARD A, GURNEY AL: FGF-19, a novel fibroblast growth factor with unique specificity for FGFR4. Cytokine 11: 729-735, 1999.

ZHANG X, YEUNG DC, KARPISEK M, STEJSKAL D, ZHOU Z, LIU F, WONG RLC, CHOW WS, TSO AWK, LAM KSL, XU A: Serum FGF21 levels are increased in obesity and are independently associated with the metabolic syndrome in humans. Diabetes 57: 1246-1253, 2008. 